\title{
Augmented Reality in Electrical Fundamentals
}

\author{
http://dx.doi.org/10.3991/ijoe.v10i6.4030 \\ M.T. Restivo ${ }^{1}$, F. Chouzal ${ }^{1}$, J. Rodrigues ${ }^{1}$, P. Menezes ${ }^{2}$, B. Patrão ${ }^{2}$ and J. B. Lopes ${ }^{3,4}$ \\ ${ }^{1}$ University of Porto, Porto, Portugal \\ ${ }^{2}$ University of Coimbra, Coimbra, Portugal \\ ${ }^{3}$ CIDTFF - Research Centre "Didactics and Technology in Education of Trainers" \\ ${ }^{4}$ Universidade de Trás-os-Montes e Alto-Douro, Vila Real, Portugal
}

\begin{abstract}
The use of emergent technologies in the classroom is mandatory since very early stages considering their presence everywhere, from entertainment to the advertisement areas. Recognizing that fundamentals in electricity have very low level of popularity in secondary schools, different applications have been developed to test the interest of following in the future other developing tools in this field based in augmented reality technologies. The work describes the use of one of the applications tested with students 12 to 14 years old in terms of adequacy, student engagement and student achievement of specific goals. A technical short description is included as well as the implementation of the test with secondary students. Results from this study show that the use of AR applications has effective potential to be used in the classroom as an experimental tool, stimulates student engagement in class activities and enables students to build a self-efficacy in AR use being a good predictor for students' learning.
\end{abstract}

Index Terms-augmented reality; computer aided instruction; distance learning; electronic learning; passive circuits.

\section{INTRODUCTION}

Experimentation is widely accepted as being a fundamental activity for the learning processes. Being it either staged or left open, its importance comes from the implied reflection on doing. Unfortunately it is not always possible to have students doing experimentation in the classroom due to lack of time, materials, etc., and leaving them to do it by themselves in their spare time brings additional risks, especially in the manipulation of hazardous materials.

The use of emergent technologies can offer new ways of making both supervised and unsupervised experiments available to most students.

Online experimentation, comprising remote and virtual experimentation aided by virtual reality components, augmented reality, sensorial devices, live videos and other tools as interactive videos and serious games which promote user immersion in virtual environments recreating the real experience [1], accomplishes two fundamental purposes in the learning settings. It permits students to observe and describe how real systems work particularly by checking effects when changing some input variables and/or system parameters. On the other hand, it can solve the great dependence from material resources and timeconsuming preparation of experimental setups to support traditional experimental settings.

Simulators have been used in many situations to observe the evolution of some system or to obtain the expectable results of some operation, based on more or less approximate models. Although they possess an unques- tionable value, simulators are not motivating, as their use requires a well-established understanding of the system before any good use can be made of it. Another aspect is the non-interactive characteristic of most simulators that normally only show the final results, frequently under the form of plots.

In fact, systems and their behaviours can be created with a high degree of realism in a virtual world generated by computer using simulators. This allows systems with high complexity and/or high cost that would otherwise be only available to specialists, to become available to be tested by everybody.

On another hand, a simulator is often the only accessible resource for initial training before the real use of a given system. Flight simulators are examples of systems that can be used to "pre"-train people before they start training at the controls of complex systems. Although a flight simulator cannot fully reproduce the sensation of piloting a plane, it can play an important role in learning of procedural sequences or of how to react to some situations without undertaking any risks.

Enhancing simulators with virtual or augmented reality interfaces can lead to a higher-level experience in which the user can explore a large number of systems and situations, e.g. see what happens inside a jet engine, or try to practice some type of surgery. These systems can provide an added feeling of presence and immersion of great value in education and training. In fact, feelings like "I was there" and "I felt" are two key ingredients of unforgettable experiences [2].

The virtual reality (VR) concept exists since the $1960 \mathrm{~s}$, and it is considered a very promising, powerful and useful tool, especially in the engineering fields.

Augmented reality (AR), instead of transporting the user to a virtual environment as VR does, mixes the virtual elements with the real world. Consequently the user perceives his/her surrounding environment with added virtual objects that can be modified by the environment itself, or by the user. This provides the necessary ingredients for creating virtual instruments, tools, or components that may be manipulated by the user to accomplish some mission, to perform an experiment, etc.

This article describes the development of an AR-based application that using these perspectives, targets to offer multiple forms of experiential learning support.

This example, hereafter described, intends to explore the basics of DC circuits and is addressed to STEM education. The developed AR application, simple and easy to use, aims at being available to all at home and school, and only needs a computer with Internet access and a webcam 
connected to it. This application has been used to evaluate the educational potential of AR applications in the classroom in terms of:

- Whether the AR application can be used viably in the classroom as an "experimental" tool for students 12 to 14 years old;

- How students use the AR application in class and how is their level of engagement in the activities;

- The reported student self-efficacy [3] about their use of the AR application, and confidence about their ability to do other tasks.

\section{AUGMENTED REALITY AND DC CiRCUIT FUNDAMENTALS}

\section{A. Developed Application}

The AR application is part of the online experimentation available at the ONLINE EXP FEUP of Faculty of Engineering of the University of Porto at http://onlinelab.fe.up.pt/

Different resources are grouped into three main areas: Remote Experimentation, Simulations and Virtual Reality with sensorial interaction and augmented reality http://onlinelab.fe.up.pt/ar_exp.html

The developed application aims to contribute to the understanding of certain basic concepts related to direct current electrical circuits (DC circuits), namely power supply, driven current, circuit components such as lamps, motor, switch, etc., as well as open/closed circuit, short circuit, current direction, power dissipation, series/parallel components, etc.

A battery, a few lamps, a dc motor, a switch and connecting wires are provided to the user considering that any electrical basic circuit includes a power supply, a power dissipating component and a switch connected by conducting wires.

The AR system of marker-based type is based on a set of markers associated with different circuit elements: the circuit structure supported by the connection wires, Fig. 1, and the components - one battery, one switch, one DC motor and two lamps, Fig. 2.

Using the markers like LEGO pieces, the challenge is to understand the evidence of circuit operation and to perceive different situations or even practice the implementation of possible alternative solutions. The user may interact with the circuit by actuating the switch, combining elements association, changing the battery position or just rotating it, etc., by simply handling the markers.

The easy handling configuration and rapid reconfiguration of the circuit allows immediate comparison (use of short-term memory), leading users to ask themselves the reason of the circuit behaviour in each particular configuration. Concepts like current direction, power dissipation, motor rotating direction, open/closed circuit, parallel/series association are easily observed and tested.

The components are integrated in the circuit by placing the respective marker in one of the free positions of the circuit that will be viewed by the webcam. The image processing is performed using the JavaScript library, JSARtoolKit, leading to the creation of the respective 3D image by using the modeling program Blender3D. It is not necessary to fill all the available positions, since the implemented circuit is a closed circuit.

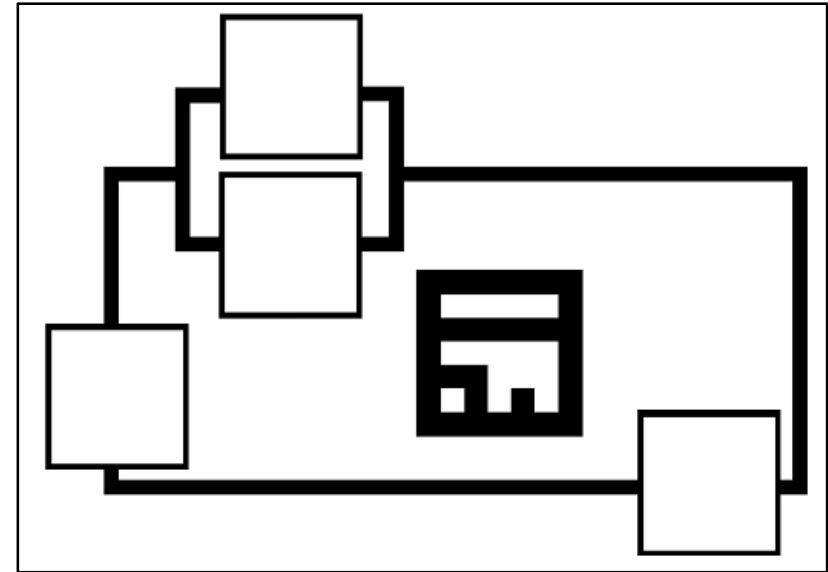

Figure 1. Augmented reality DC circuit marker.
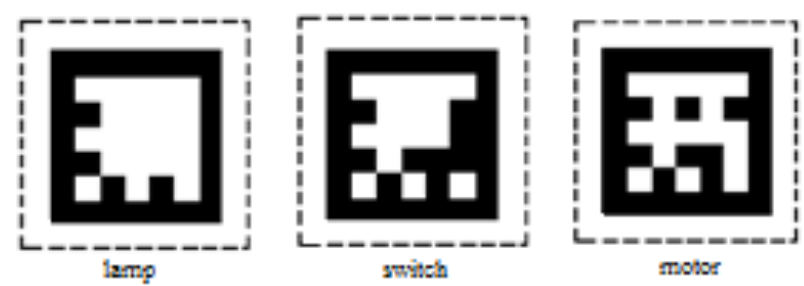

mootor
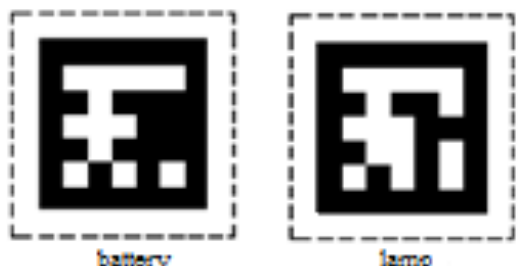

Figure 2. Augmented reality DC circuit components markers.

To avoid any image processing limitation performed by current equipment turning into an unstable operation, some simplification is advisable. This means that lamps and motor markers should not be always present in the camera view field but only when the user builds the circuit.

The AR application does not require the installation of any plug-in [4]. Using the Google Chrome web-browser, the access to the webcam image and the use of WebGL [5, $6]$ is supported natively. This permits it to be available to anyone, anywhere through an internet address, as is the present case. By accessing it anyone can print the markers and the circuit. By using a webcam it is possible to "play the game" and to explore it.

\section{B. Educational Potential}

Any tool as is the case of the present application based on AR can have the characteristics of a learning object if it is manageable [2] and if it promotes the interaction of the user with the reality under study [7] by exploring its configurations.

If these requirements are met, cognitive and emotional experiences may provide new insights into what the students are studying. An AR application (in this case DC electrical circuits) may have the potential of a simulation increased by the manipulation of objects (markers that can be handled and observed as electrical components).

In conclusion, the educational potential of this specific AR application will be demonstrated if $[8,9]$ : 
- It allows intuitively to bring the reality into study;

- It provides emotional and cognitive experiences that involve students in the rational learning effort;

- It provides correct information about the system according to different settings, which are relevant to test ideas and their feasibility;

- It permits new ways of representing the reality under study.

\section{DESCRIPTION OF EXPLORATORY STUDY}

Like any educational resource the developed application needs exploratory studies in real situations to be tested and to lead to later improvements and to evaluate if its potential is confirmed $[10,11]$. Therefore, an exploratory study was conducted involving the use of the AR DC circuit as an experimental tool in the classroom to evaluate the achievement of the three aims defined in section I.

\section{A. Participants}

The AR application was used in two groups of a senior teacher in a secondary school, in northern Portugal. The classes were held in the laboratory environment.

One sample of students $\left(n_{1}=10\right)$ was recruited in a $9^{\text {th }}$ level class and it was divided into 3 groups. These students had already addressed electrical circuit topics in their lessons. The other sample $\left(\mathrm{n}_{2}=11\right)$ was recruited in an $8^{\text {th }}$ level class and it was divided into 3 groups who never had discussed topics related to electrical circuits.

\section{B. Implementation}

The elementary concept of AR was briefly explained. Then the AR DC circuit application was presented, explained and demonstrated using the material of the AR application and a written general instruction in the worksheet was provided.

Students were distributed by worktables, Fig 3. Each group had the following material: a printed circuit and 5 single markers for each electrical component (two lamps, one switch, one motor, one battery) as those in Fig. 1, a laptop with internet access (and so to the AR application), and one webcam.

The proposed activity had four tasks:

- Task 1: Electric circuit assembly using four of the five components in order to guaranty a) a working circuit configuration; b) a not working circuit configuration.

- Task 2: Electric circuit assembly assuring that only one lamp is on, excluding the use of the DC motor.

- Task 3: Electric circuit assembly using two lamps, assuring that one would be brighter than the other.

- Task 4: Electric circuit assembly using two lamps, considering the battery in a fixed position according to the provided instructions, in order a) to get the maximum brightness; b) to get minimum brightness.

After explaining the tasks the teacher was simply observing the students and helping them if they had questions. The time assigned to the tasks was 25 minutes. The remaining time, 20 minutes, was used for the opening activity introduction and later student survey.

The collected data involved: the survey on students perceptions about their experience and self-efficacy related to the use of the AR application and information gathered by teacher observation during activity progressin the class-

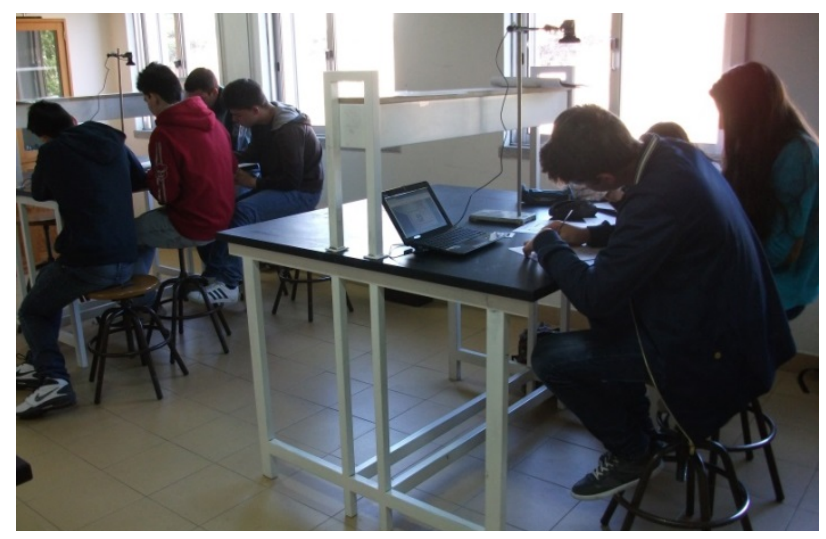

Figure 3. AR application used in experimental class (9th level-14 years old).

room (field notes of an external observer, audio recording of a group progress, screen capture in all groups, photos and registration of students' writing activity).

\section{Data analysis}

Observation data were analyzed based on the following three dimensions: the potential configuration of reality under study, the involvement of students during AR application use and the effective use of the AR application as an experimental tool.

Survey data were analyzed to characterize how students perceived their experience and their level of satisfaction using AR application and also to characterize the students' self-efficacy about the use of AR.

\section{RESUlts}

\section{A. Using the AR DC Circuit in Classroom as an Experimental Tool}

The observation data during the classroom test session it leads to the following conclusions:

- All groups attempted to solve the tasks using the AR tool. The students manipulate the AR tool and write notes and answers to the tasks in their notebooks. The major part of the answers was correct.

- The students were engaged with the AR tool. The use of the AR tool enables them to be concentrated in tasks: they do not talk about other issues; only occasionally the teacher's help; some of them remained finishing his/her task during playground time.

- It was found that the assembly process of the electric circuit is very intuitive for students. The teacher noticed that the students in the $8^{\text {th }}$ level (with no previous knowledge of the subject) have attempted to reach a circuit configuration with the AR tool to respond to the tasks more freely.

- The AR tool allows several configurations as possible answers within a task. Figure 3 illustrates some possible configurations used by students to respond to the task 2.

- The configuration and reconfiguration of the circuit can be achieved quickly and this allows students a more immediate comparison (using short-term memory) enabling them to understand different functional aspects. For example, Fig. 4 presents two DC circuit configurations of $8^{\text {th }}$ level students allowing to convey the concept of closed electrical circuit. 


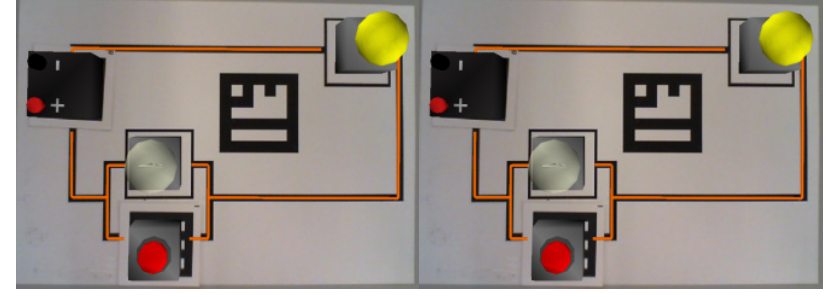

a)

b)

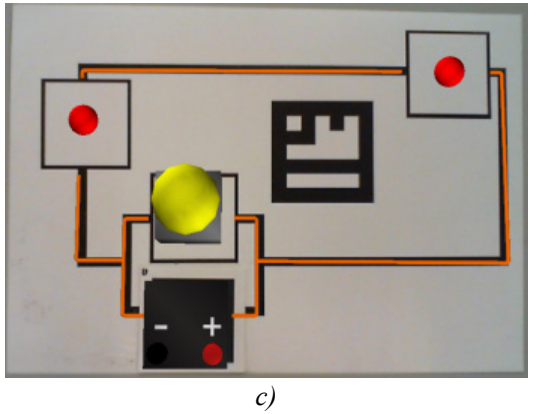

Figure 4. Configuration of answers to task 2 - a) group of $9^{\text {th }}$ level class, b) and c) groups of $8^{\text {th }}$ level class.
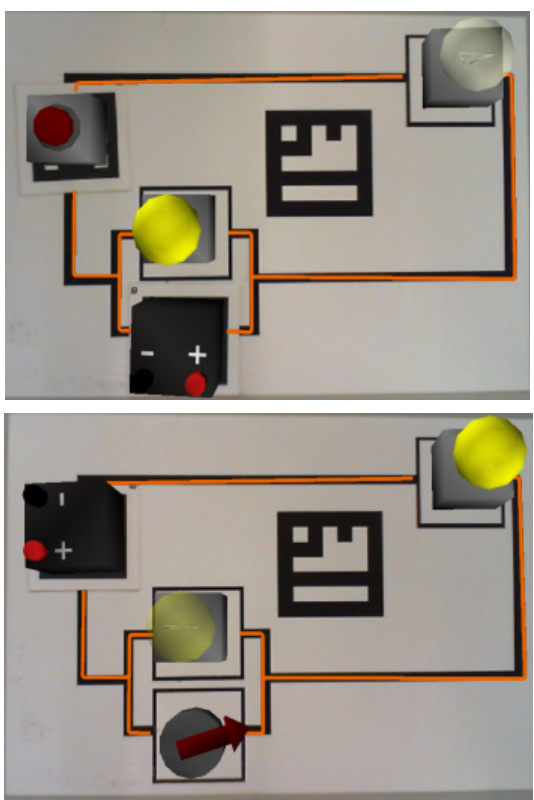

Figure 5. Configurations obtained by a group of $8^{\text {th }}$ level to answer task 1 .

\section{B. Students' Perceptions and Self-Efficacy}

Table 1 shows the survey results. Six answer levels have been used (from "totally disagree" to "totally agree") to avoid centered answers.

The survey integrates seven questions. Four questions were used to evaluate the students' self-efficacy, this is, their personal perception of their own competence to deeply explore the learning tool. Additionally, it integrates three more questions to evaluate the students' satisfaction using the tool and their learning with it.

The results show that the students from both levels have shown confidence while using this tool for: (a) performing any task, (b) experimenting and understanding the correctness of their answers, (c) coming up with questions, (d) explaining someone else what they have learned. The main difference between the two classes is that the $8^{\text {th }}$ grade students were more confident with the use of the
AR tool to satisfy their curiosity about how DC circuits work (question 3, Table I).

Finally, students were happy, in general, with their personal experience when using the present AR tool (AR operation and handling tasks) and with what they learned during the activity (questions 5 to 7, Table I).

TABLE I.

TYPE SIZES FOR CAMERA-READY PAPERS

\begin{tabular}{|c|c|c|c|c|c|c|c|}
\hline Questions & & $\mathrm{TD}$ & $\mathrm{D}$ & SD & SA & A & TA \\
\hline \multicolumn{8}{|c|}{ Self-efficacy (personal perception of competence) } \\
\hline \multirow{2}{*}{$\begin{array}{l}1-\text { I can perform any task } \\
\text { doing experiences with the } \\
\text { AR DC circuit }\end{array}$} & $9^{\text {th }}$ & & & & & 9 & 1 \\
\hline & $8^{\text {th }}$ & & & & 3 & 7 & 1 \\
\hline \multirow{2}{*}{$\begin{array}{l}2 \text { - I can know whether the } \\
\text { answers are correct doing } \\
\text { experiences with this AR } \\
\text { tool }\end{array}$} & $9^{\text {th }}$ & & & & & 9 & 1 \\
\hline & $8^{\text {th }}$ & & & & 1 & 8 & 2 \\
\hline \multirow{2}{*}{$\begin{array}{l}3-\text { I can ask questions to } \\
\text { verify the answer experi- } \\
\text { menting with this AR tool }\end{array}$} & $9^{\text {th }}$ & & & & 5 & 3 & 2 \\
\hline & $8^{\text {th }}$ & & & & & 10 & 1 \\
\hline \multirow{2}{*}{$\begin{array}{l}4 \text { - I can explain to other } \\
\text { person what I have learned } \\
\text { today }\end{array}$} & $9^{\text {th }}$ & & & & 2 & 6 & 2 \\
\hline & $8^{\text {th }}$ & & & & 1 & 8 & 2 \\
\hline \multicolumn{8}{|l|}{ Satisfaction } \\
\hline \multirow{2}{*}{$\begin{array}{l}5 \text { - The AR application is } \\
\text { friendly handling }\end{array}$} & $9^{\text {th }}$ & & & & 3 & 2 & 5 \\
\hline & $8^{\text {th }}$ & & & & 1 & 5 & 5 \\
\hline \multirow{2}{*}{$6-\mathrm{I}$ enjoy this AR tool } & $9^{\text {th }}$ & & & & 1 & 3 & 6 \\
\hline & $8^{\text {th }}$ & & & & 3 & 4 & 4 \\
\hline \multirow{2}{*}{$\begin{array}{l}7 \text { - I have learned with this } \\
\text { AR tool }\end{array}$} & $9^{\text {th }}$ & & & & 2 & 3 & 5 \\
\hline & $8^{\text {th }}$ & & & & 2 & 4 & 5 \\
\hline
\end{tabular}

\section{FINAL COMMENTS}

Having in mind that hands-on activity has their place in STEM classrooms, the results of the exploratory study enable to show that:

- The AR tool can be used in classroom environment as an online experimental tool, available to everyone, anywhere, to observe and describe how DC circuits work and to convey related concepts and to stimulate the learning by doing approach. In fact, the results about class observation elicit that the AR tool: (i) allows to intuitively bring the reality into study; (ii) provides emotional and cognitive experiences that involve students in the rational learning effort; (iii) gives correct information about the system according to the settings, which are relevant to test ideas and their feasibility.

- The use of the AR tool by students is pleasant for them, by increasing their satisfaction and engagement, by developing the students' perception about their competence to deal with curriculum concepts or even for those not yet introduced to the DC circuits' topic.

- This study complements positively another one reported in [12], performed in a particular group of STEM students who were stimulated by being integrated in a summer short course in Faculty of Engineering of University of Porto.

- The authors hope to have made available a tool which can be used in any context and hope to receive additional feedback in the near future. 


\section{REFERENCES}

[1] M.T. Restivo and A. Cardoso, "Exploring Online Experimentation", Guest editorial iJOE Vol 9 (2013), pp 4-6, http://dx.doi.org/10.3991/ijoe.v9iS8.3448

[2] T. Knuuttila, "Models, representation, and mediation". Philosophy of Science, vol. 72(5), pp. 1260-1271, 2005. http://dx.doi.org/ $10.1086 / 508124$

[3] B.J. Zimmerman, "Self-efficacy: An essential motive to learn." Contemporary educational psychology, vol. 25(1), pp 82-91, 2000. http://dx.doi.org/10.1006/ceps.1999.1016

[4] B. Lawson, R. Sharp, Introducing HTML5, $2^{\text {nd }}$ edit., New Riders, 2012.

[5] D. Cantor, B. Jones, WebGL Beginner's Guide, Packt Publishing, 2012.

[6] T.Parisi, WebGL: Up and Running, O'Reilly, 2012.

[7] A. Damasio, "Self Comes to Mind: Constructing the Conscious Brain" ( $1^{\text {st }}$ ed.), USA: Pantheon, 2010.

[8] J. Vallverdú, "Seeing for Knowing: The Thomas Effect and computational sciences", In Thinking Machines and the Philosophy of Computer Science: Concepts and Principles [ $7^{\text {th }}$ European Conference on Computing and Philosophy (ECAP09), Catalonia (p. 280293), 2010].

[9] L. K. Smetana and R. L. Bell, "Computer Simulations to Support Science Instruction and Learning: A critical review of the literature". International Journal of Science Education, vol. 34(9), 1337-1370, 2012. http://dx.doi.org/10.1080/09500693.2011. $\underline{605182}$

[10] S. B. McKagan, K. K. Perkins, M. Dubson, C. Malley, S. Reid, R. LeMaster, and C. E. Wieman, "Developing and Researching PhET simulations for Teaching Quantum Mechanics", American Journal of Physics, vol. 76(4), pp. 406-417, 2008. http://dx.doi.org/10.1119/1.2885199

[11] J.C. Marques, M.T. Restivo and M.F. Chouzal, "Mentoring Activities in a Summer School", iJOE, Vol. 3, 2013, doi http://dx.doi.org/10.3991/ijep.v3iS1.2407

[12] T.Restivo, F.Chouzal, J.Rodrigues, P.Menezes and J.B. Lopes, “Augmented Reality to Improve STEM Motivation”, [ITEP'14, EDUCON 2014, Turkey, 2014].

\section{AUTHORS}

M.T. Restivo, F. Chouzal and J. Rodrigues are with the Institute of Mechanical Engineering (IDMEC)-FEUP, University of Porto, Portugal, (trestivo@fe.up.pr, jose.c.rodrigues@gmail.com, fchouzal@fe.up.pt).

P. Menezes, B. Patrão are with Instituto de Sistemas e Robótica, University of Coimbra, Portugal (paulo@isr.uc.pt, bpatrao@isr.uc.pt).

J.B.Lopes is with Research Centre "Didactics and Technology in Education of Trainers"- CIDTFF and with Universidade de Trás-os-Montes e Alto-Douro, Vila Real, Portugal (blopes@utad.pt).

The work was developed under Experiment@Portugal 2012 project funded by Calouste Gulbenkian Foundation. The described activities are also in line with works within PEst-OE/EME/LA0022/2013, FCT. This article is an extended and modified version of a paper presented at the EDUCON2014 conference held at the Military Museum and Cultural Center, Harbiye, Istanbul, Turkey, 3-5 April 2014. Submitted 11 July 2014. Published as resubmitted by the authors 25 October 2014. 